OPEN ACCESS

Edited by:

Guido Moll,

Charité-Universitätsmedizin Berlin, Germany

Reviewed by: Mehdi Najar, Université libre de Bruxelles, Belgium Selim Kuci,

University Hospital Frankfurt, Germany

*Correspondence: Raghavan Chinnadurai chinnadurai_r@mercer.edu

Specialty section: This article was submitted to Alloimmunity and Transplantation,

a section of the journal

Frontiers in Immunology

Received: 12 May 2021 Accepted: 01 July 2021

Published: 26 July 2021

Citation:

Chinnadurai $R$, Bates $P D$, Kunugi $K A$, Nickel KP, DeWerd LA, Capitini CM,

Galipeau J and Kimple RJ (2021)

Dichotomic Potency of IFN Licensed Allogeneic Mesenchymal

Stromal Cells in Animal Models of Acute Radiation Syndrome and Graft Versus Host Disease.

Front. Immunol. 12:708950. doi: 10.3389/fimmu.2021.708950

\section{Dichotomic Potency of IFN $\gamma$ Licensed Allogeneic Mesenchymal Stromal Cells in Animal Models of Acute Radiation Syndrome and Graft Versus Host Disease}

\author{
Raghavan Chinnadurai ${ }^{1 *}$, Paul D. Bates ${ }^{2}$, Keith A. Kunugi ${ }^{3}, K_{\text {Kwangok P. Nickel }}^{4}$, \\ Larry A. DeWerd ${ }^{3}$, Christian M. Capitini ${ }^{2,5}$, Jacques Galipeau ${ }^{5,6}$ and Randall J. Kimple ${ }^{4,5}$ \\ ${ }^{1}$ Department of Biomedical Sciences, Mercer University School of Medicine, Savannah, GA, United States, ${ }^{2}$ Department of \\ Pediatrics, University of Wisconsin School of Medicine and Public Health, Madison, WI, United States, ${ }^{3}$ Department of \\ Medical Physics, University of Wisconsin School of Medicine and Public Health, Madison, WI, United States, ${ }^{4}$ Department of \\ Human Oncology, University of Wisconsin School of Medicine and Public Health, Madison, WI, United States, ${ }^{5}$ University of \\ Wisconsin Carbone Cancer Center, University of Wisconsin School of Medicine and Public Health, Madison, WI, United States, \\ ${ }^{6}$ Department of Medicine, University of Wisconsin School of Medicine and Public Health, Madison, WI, United States
}

Mesenchymal stromal cells (MSCs) are being tested as a cell therapy in clinical trials for dozens of inflammatory disorders, with varying levels of efficacy reported. Suitable and robust preclinical animal models for testing the safety and efficacy of different types of MSC products before use in clinical trials are rare. We here introduce two highly robust animal models of immune pathology: 1) acute radiation syndrome (ARS) and 2) graft versus host disease (GvHD), in conjunction with studying the immunomodulatory effect of well-characterized Interferon gamma (IFN $\gamma$ ) primed bone marrow derived MSCs. The animal model of ARS is based on clinical grade dosimetry precision and bioluminescence imaging. We found that allogeneic MSCs exhibit lower persistence in naivve compared to irradiated animals, and that intraperitoneal infusion of IFN $\gamma$ prelicensed allogeneic MSCs protected animals from radiation induced lethality by day 30 . In direct comparison, we also investigated the effect of IFN $\gamma$ prelicensed allogeneic MSCs in modulating acute GvHD in an animal model of $\mathrm{MHC}$ major mismatched bone marrow transplantation. Infusion of IFN prelicensed allogeneic MSCs failed to mitigate acute GvHD. Altogether our results demonstrate that infused IFN $\gamma$ prelicensed allogeneic MSCs protect against lethality from ARS, but not GVHD, thus providing important insights on the dichotomy of IFN prelicensed allogenic MSCs in well characterized and robust animal models of acute tissue injury.

Keywords: mesenchymal stromal/stem cells, interferon- $\gamma$, cell therapy, acute radiation injury, bone marrow transplantation, animal model 


\section{Dichotomic Potency of IFN $\gamma$ licensed allogeneic MSCs in animal models}

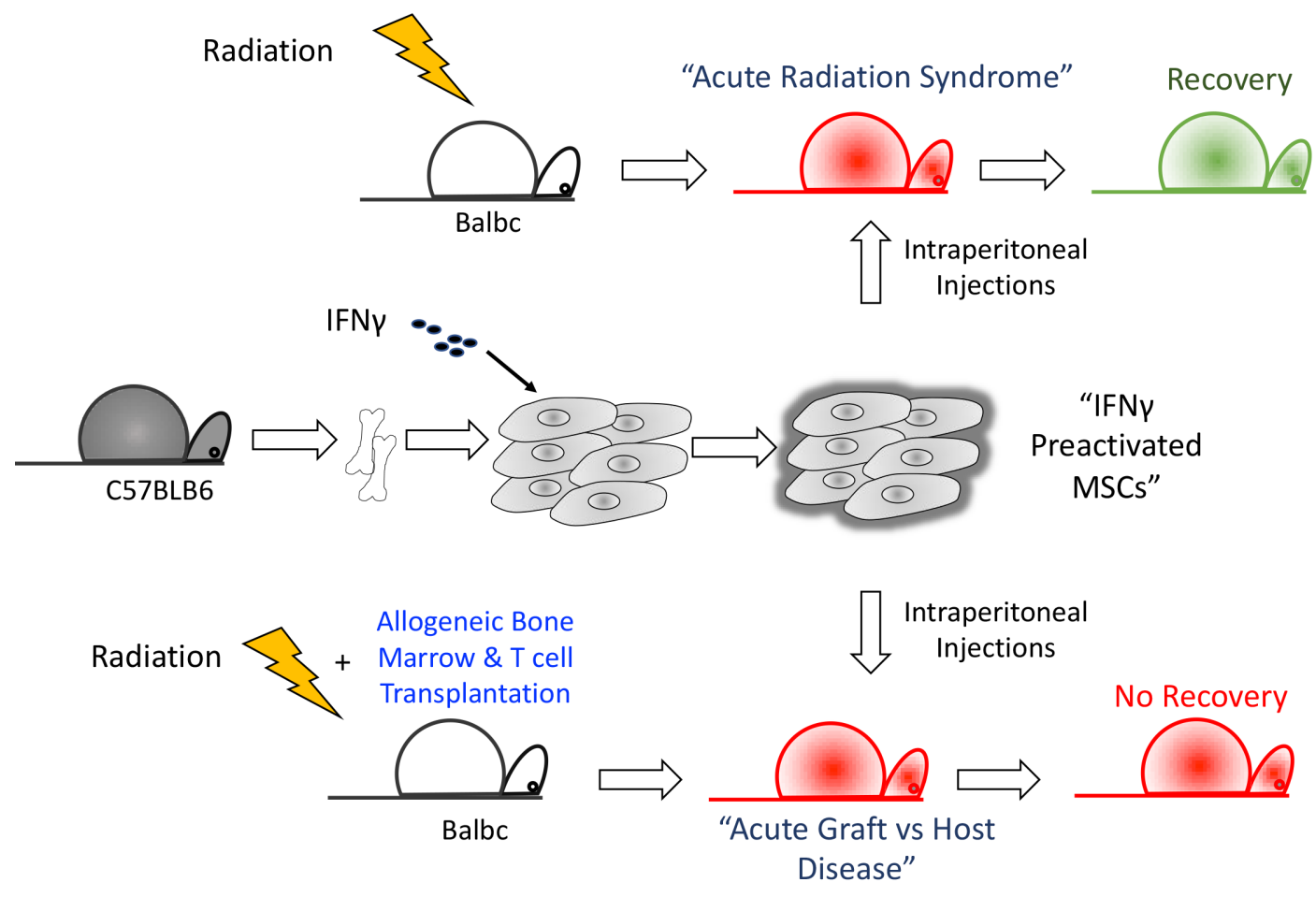

GRAPHICAL ABSTRACT |

\section{INTRODUCTION}

Mesenchymal stromal cells (MSCs) are approved in Europe for the treatment of complex perianal fistulas from Crohn's disease and in Japan for steroid-refractory acute graft versus host disease (GvHD). MSCs are also in cell therapy in clinical trials for the treatment of a variety of inflammatory and degenerative disorders (1). Preliminary studies have showed that MSCs possess a myriad of regenerative and immunomodulatory properties and an excellent safety profile $(2,3)$. MSCs can be obtained from either random healthy donors (i.e. allogeneic) or from individual patients (i.e. autologous), and can be derived from multiple tissues sources including bone marrow, adipose tissue, placenta, or umbilical cord tissue (4). The use of autologous MSCs avoids potential immune-mediated tissue mismatch reactions $(5,6)$. However, allogeneic MSCs showed promising clinical benefits in mitigating steroid resistant Graft vs. Host Disease (GvHD) and perianal fistula in Crohn's Disease (7-9).

While there is certainly an appeal to using autologous MSCs as the preferred source for personalized cell therapy of chronic diseases to prevent MSC rejection, the use of off-the-shelf allogeneic MSCs is more feasible for the treatment of acute inflammatory disorders which preclude the ability to harvest, isolate, and expand autologous MSCs that may have been damaged during acute tissue injury. In addition, the timing of cell therapy is significant in rescuing patients with acute illness, which is only possible with allogeneic/random donor MSC approach. Examples of this include mass casualty events causing acute radiation syndrome from exposure to Ionizing Radiation (IR) and the development of steroid resistant acute GvHD. With an allogeneic cell therapy approach, MSCs from random donors can be isolated, expanded, cryopreserved and banked as cell therapy products in advance. At the time of acute tissue injury, allogeneic MSCs can be thawed and infused into the patients immediately without the delay of lengthy cell manufacturing procedures (10). Further evidence is needed in defining which acute tissue injury conditions are amenable to the benefits of allogeneic MSCs in animal models.

Previous studies have demonstrated that IFN $\gamma$ substantially improved the immunomodulatory and regenerative properties of MSCs and thus it can be an augmented cell therapy for mitigating acute tissue injury $(11-15)$. IFN $\gamma$ prelicensed allogeneic MSCs potency needs to be validated in the related animal models of acute injury. In this report, IFN $\gamma$ prelicensed allogeneic MSCs were tested as a cell therapy in two models of acute tissue injury: (1) lethal ARS and (2) GvHD. 


\section{MATERIALS AND METHODS}

\section{Murine Bone Marrow MSCs and IFN $\gamma$ Licensing}

All animal studies were approved by the Institutional Animal Care and Use Committee (IACUC) University of WisconsinMadison and Mercer University. Murine MSCs were isolated from bone marrow from the femurs and tibia of C57BL/6 animals and cultured in complete DMEM (Corning, MA, USA) (15-20\% fetal bovine serum (Sigma, MO, USA) and 100U/mL penicillin/streptomycin (Corning, MA, USA). Cells were passaged/sorted to remove adherent CD45+ cells. MSC identity was confirmed as described previously (16). MSCs were used from the early passage proliferative phase. We confirm the viability of MSCs (above $90 \%$ viability) prior to infusion into the animals using trypan blue exclusion analysis. $20 \mathrm{ng} / \mathrm{mL}$ IFN $\gamma$ was added to MSCs and 48 hours later, cells were harvested. Exogenous IFN $\gamma$ was washed and licensed MSCs were injected fresh into animals within 30-60 minutes post harvesting from the culture. IFN $\gamma$ licensing of MSCs is confirmed with the evaluation of the upregulation of MHC-Class I and MHC class II expression by flow cytometry (Figure S1).

\section{ARS Model and IFN $\gamma$ Licensed MSC Treatment}

9 to 12 week old Balb/c animals were purchased from Jackson Laboratories (Bar Harbor, ME). Male and female animals were used to identify gender susceptibility to irradiation. Male animals were exclusively used when testing MSC therapy. One day prior to irradiation, animals were treated with Uniprim ${ }^{\mathrm{TM}}$ (Envigo, USA) and were maintained with uniprim ${ }^{\mathrm{TM}}$ diet throughout the entire experiment. On the morning of study Day 0, mice are placed in single chambers of a Plexiglas irradiation apparatus and exposed to a single uniform TBI $6 \mathrm{MV}$ photon irradiation from the Varian 21EX Linear Accelerator (linac) (Varian Medical Systems, Palo Alto, CA) and were irradiated with the designated dose. After 4 hours rest, animals were subjected to a second dose of irradiation. Day 1 and Day 8 post irradiation cycle, IFN $\gamma$ prelicensed MSCs or PBS were given. After first week animals were supplemented with hydrogel mixed with Uniprim $^{\mathrm{TM}}$ diet. Animals were monitored daily for body weight and Mouse Intervention Scoring System (MISS) score as previously described (17). Mice that reached MISS score of 12 were euthanized as described previously (17).

\section{Allogeneic Bone Marrow Transplantation and IFN $\gamma$ Licensed MSC Treatment}

C57BL/6 donor mice were euthanized by $\mathrm{CO}_{2}$ asphyxiation. Bone marrow $(\mathrm{BM})$ cells were harvested from the tibias and fibulas using mortar and pestle and depleted of erythrocytes using ACK Lysing Buffer (Lonza, Walkersville, MD). CD3 microbeads were used on single-cell suspensions to deplete $\mathrm{T}$ cells using the AutoMACS Pro separation system (Miltenyi Biotec, Auburn, CA). Splenic T cells were isolated by negative selection. $4+4 \mathrm{~Gy}$ irradiated Balb/c animals were injected intravenously with C57BL/6 T cell depleted BM (5X10 ${ }^{6}$ Cells) and T cells $\left(2 \times 10^{6}\right.$ Cells, $1 \times 10^{6}$ and $\left.0.5 \times 10^{6}\right)$ on the same day. $\mathrm{BM}$ alone group received only $\mathrm{T}$ cell depleted C57BL6 BM and not C57BL/6 splenic T cells. IFN $\gamma$ licensed MSCs were infused intraperitoneally on days 2 and 8 . In some situations, treatment was performed on days 1,3 and 5. Control group received only PBS. Mice were weighed individually biweekly, and the mean weight of each treatment group was calculated at each time point and was compared with the day 0 weight. Examination for moribund mice was performed by a veterinarian and veterinary technicians who were blinded to the experimental groups, and assessed the mice daily in accordance with approved institutional protocols.

\section{Bioluminescence Imaging}

Luciferase transgenic murine MSCs (C57BL/6 background) were isolated as described previously (12). After IFN $\gamma$ licensing $(20 \mathrm{ng} / \mathrm{mL}$ for 48 hours), exogenous IFN $\gamma$ was washed and harvested cells were injected subcutaneously into naïve and irradiated animals. Each animal received subcutaneous injection of MSCs in both of its flanks. Subsequently, bioluminescence imaging was performed longitudinally on specified time points. Animals were anesthetized by isoflurane gas chamber. Subsequently, luciferin substrate was injected intraperitoneally and the animals were placed in an IVIS spectrum imager (Perkin Elmer, Waltham, MA, USA) with nose cones attached to an isoflurane gas chamber. Imaging was performed within 5-8 minutes post luciferin injection. Bioluminescence signal (Total flux) was analyzed using Living Image software (Perkin Elmer, Waltham, MA, USA) by creating a region of interest over each animal. Measurements were recorded as photons $/ \mathrm{s} / \mathrm{cm}^{2}$. Fold change in total flux was calculated based on the control animal that did not receive luciferase MSCs.

\section{Statistical Analysis}

Statistical analysis was performed in GraphPad prism 8 software (GraphPad Software, San Diego, USA). An unpaired twosided $t$-test was used to determine significance between the means of two groups. Kaplan Meier survival curve analysis was performed to determine the difference in percentage survival of animals between two groups. A two-sided $p$ value $<.05$ was considered statistically significant.

\section{RESULTS}

\section{Development of Animal Model of Radiation Injury With Clinical Grade Precision Dosimetry}

We utilized Balb/c mice due to their sensitivity to radiation and well-established ARS. An important issue in translating animal model of IR induced ARS is the lack of precision in radiation dose that are being used in conventional irradiators. To overcome this challenge, we have developed a model of radiation injury by integrating National Institutes of Standards and Technology (NIST)-compliant clinical grade precision dosimetry. Animals were irradiated in a Varian 21EX Linear Accelerator (Linac) with single uniform TBI $6 \mathrm{MV}$ photon 
irradiation. Linac output dosimetry rigor was verified with mouse shaped phantoms to ensure the validity of doses delivered. Each mouse irradiation cycle was verified using thermoluminescent dosimeters (TLD) $1001 \mathrm{~mm}^{3}$ microcubes inside anatomically correct $3 \mathrm{D}$-printed mouse phantoms (Figure 1A). TLDs were calibrated utilizing a ${ }^{60} \mathrm{Co}$ irradiator directly traceable to NIST, as previously described (18). The uncertainty of the TLD measurements is $<3.0 \%$ (Figure 1B). Male and female Balb/c animals were subjected to $9 \mathrm{~Gy}$ and $7 \mathrm{~Gy}$ total body irradiation in a single fraction. We noticed that males were more sensitive to IR induced lethality than females (Figures 1C, D). 9Gy and 7Gy irradiation caused more than $50 \%$ lethality at day 30 in males due to ARS. Hence, to minimize neurotoxicity we performed split doses of $4+4 \mathrm{~Gy}$ irradiation with a four to five-hour interval between doses. We observed that more than $50 \%$ of males were dead by day 30 with split doses of $4+4 \mathrm{~Gy}$ (Figure 1E). We also observed 100\% lethality and severe ARS in females with the dose of $5+5 \mathrm{~Gy}$ while $4+4 \mathrm{~Gy}$ had no effect on females (Figure 1F). Since $5+5$ Gy in females caused severe ARS, we chose to utilize males with $4+4 \mathrm{~Gy}$ split dose IR as an optimal animal model to inform responsiveness to MSC therapy.
A

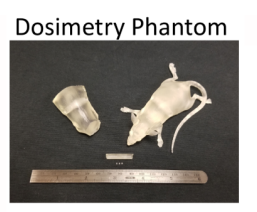

B

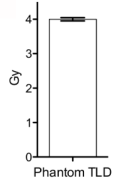

C

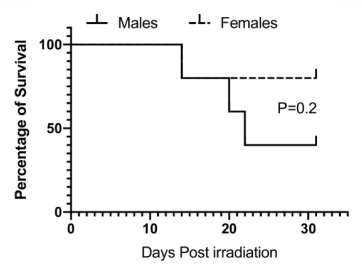

E $\quad 4+4 \mathrm{~Gy}$

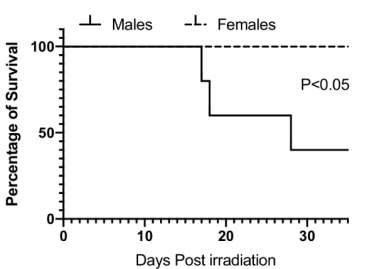

D $\quad 9$ Gy

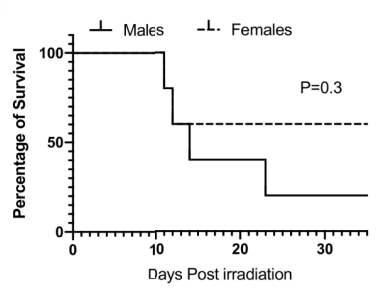

F $\quad$ Females

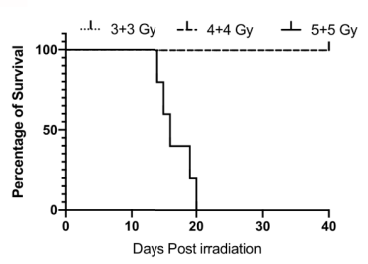

FIGURE 1 | Dosimetry and IR induced lethality in male and female Balb/c mice. (A) Murine morphic phantom of $25 \mathrm{~g}$ mouse/torso and $1 \times 1 \times 1 \mathrm{~mm}$ thermoluminescent dosimeters (TLD) cubes (white) are shown. TLDs can be placed within the mouse to confirm the delivered dose. (B) TLD measurements were shown to define the dosimetry of 4 gy IR from varian linac. Male or Female animals ( $n=5$ per group) were subjected to single dose (C) 7Gy, (D) 9Gy or split dose irradiation with 4-hour intervals (E) (4 + 4 Gy). Kaplan Meier survival curves were plotted between male and female animal groups. (F) Dose dependent split dose irradiation was tested in females.

\section{Persistence of $+/-$ IFN $\gamma$ Licensed Allogeneic MSCs in Naïve and Irradiated Animals}

To define the relative fate of +/-IFN $\gamma$ licensed allogeneic MSCs in naïve and irradiated animals, we performed bioluminescence imaging of infused MSCs from luciferase transgenic donors. +/IFN $\gamma$ licensed MSCs from luciferase transgenic C57BL/6 animals were injected subcutaneously $\left(2 \times 10^{6}\right.$ cells in each flank) into male Balb/c animals that were either naïve or $4+4 \mathrm{~Gy}$ irradiated 24 hours prior to injection. Animals were longitudinally imaged on days 1, 3, 5 and 7 post MSC injection (Figure 2A). Each set of imaging was included with control animals (without luciferase+ MSCs) and their region of interest is assigned as background luminescence. Our results demonstrated that IFN $\gamma$ licensed MSCs could be readily detected at day 1 in both naïve and irradiated animals and subsequently their signal strength got diminished over time (Figures 2A-C). We observed statistically significant higher bioluminescence signals with IFN $\gamma$ licensed MSCs compared to unlicensed MSCs in naïve animals on day 1 (Figure 2D). This difference was not observed at other time points (Figure 2E). However, we did not observe a significant difference between unlicensed and IFN $\gamma$ licensed MSCs in irradiated animals (Figure 2D). Cumulative analysis of later time points on day 5 and day 7 has demonstrated that IFN $\gamma$ licensed allogeneic MSCs were detected at the later time points in irradiated animals but not in naïve animals (Figure 2E). Altogether these results demonstrate that IFN $\gamma$ allogeneic MSCs are rejected in naïve animals over time while in the irradiated animals they are still detected at the later time points though at lower levels compared to early time points.

\section{IFN $\gamma$ Licensed Allogeneic MSCs Protect Animals From Lethal ARS}

We next investigated whether IFN $\gamma$ licensed allogeneic MSCs could mitigate IR induced lethality. MSCs derived from C57BL/6 animals were primed with IFN $\gamma$ for 48 hours before infusion. Male Balb/c animals were subjected to split doses of $4+4 \mathrm{~Gy}$ irradiation with four to four to five-hour intervals. IFN $\gamma$ licensed MSCs were infused intraperitoneally with a dose of $10^{7}$ cells per animal on day 1 (24 hours post irradiation) and day 8. Control animals received an identical volume infusion of sterile PBS. Longitudinal analysis of animal body weight and mouse intervention scoring system suggest that IFN $\gamma$ licensed allogeneic MSCs rescue animals exposed to radiation (Figures 3A, B). Survival curve analysis also has demonstrated that IFN $\gamma$ licensed allogeneic MSCs protected animals from ARS lethality by day 30 (Survival: 6/20(Control) \& 18/25(IFN $\gamma$ MSC) (Figures 3A-C). These results demonstrate that IFN $\gamma$ licensed allogeneic MSCs protect animals from lethal acute radiation syndrome.

\section{IFN $\gamma$ Primed Allogeneic MSCs Do Not Mitigate GvHD}

Next, we investigated whether IFN $\gamma$ licensed allogeneic MSCs affect GvHD induced by allogeneic bone marrow transplantation. Balb/c animals were lethally irradiated with $4+4 \mathrm{~Gy}$ and subsequently transplanted with $5 \times 10^{6} \mathrm{~T}$ cell 


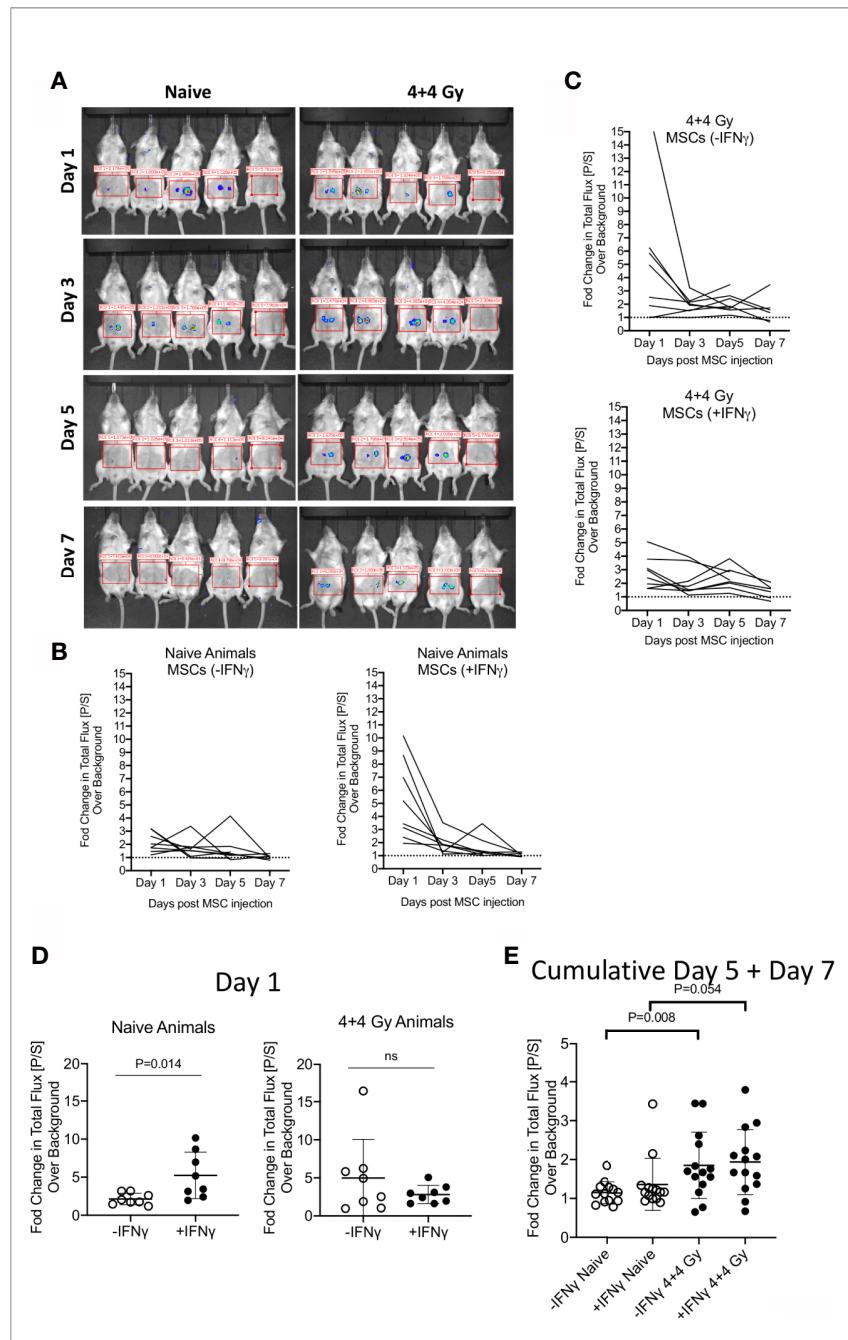

FIGURE 2 | Bioluminescence imaging of +/- IFN $\gamma$ licensed allogeneic MSCs on naive and irradiated animals. (A) Naive or $4+4$ Gy irradiated animals were subcutaneously injected with +/- IFN $\gamma$ licensed MSCs in each of the flanks. Bioluminescence imaging was performed in anesthetized animals on days 1 , 3, 5 and 7. Each imaging set was performed with 5 animals which are shown as follows. -IFN $\gamma$ MSCs (left two animals) +IFN $\gamma$ MSCs (Middle two animals) Control animal (Rightmost). Total photon flux (photons/second) in the region of interest is measured. Fold change in bioluminescence over background is shown longitudinally in (B) Naive and (C) Irradiated animals injected with +/IFN $\gamma$ licensed MSCs. (D) Changes in total flux on day 1 and (E) days $5+7$ are shown with +/- IFNg licensed MSCs in naive and irradiated animals. Two tailed unpaired $t$ test was performed in GraphPad prism to obtain statistical $p$ values. Results are shown with the cumulative from at least three independent experiments.

depleted bone marrow and $2 \times 10^{6}$ splenic T cells from C57BL/ 6 donors. Animals transplanted with only $5 \times 10^{6} \mathrm{~T}$ cell depleted bone marrow (no splenic $\mathrm{T}$ cells) were served as controls. $\mathrm{T}$ cell depleted bone marrow and splenic $\mathrm{T}$ cell transplanted animals were intraperitoneally treated with either PBS or $10^{7}$ IFN $\gamma$ prelicensed MSCs derived from C57BL/ 6 on days 2 and 8 post bone marrow transplantation (BMT). IFN $\gamma$ licensed MSCs did not provide any protection from lethal GvHD (Figure 4A). Even with reduced T cell doses

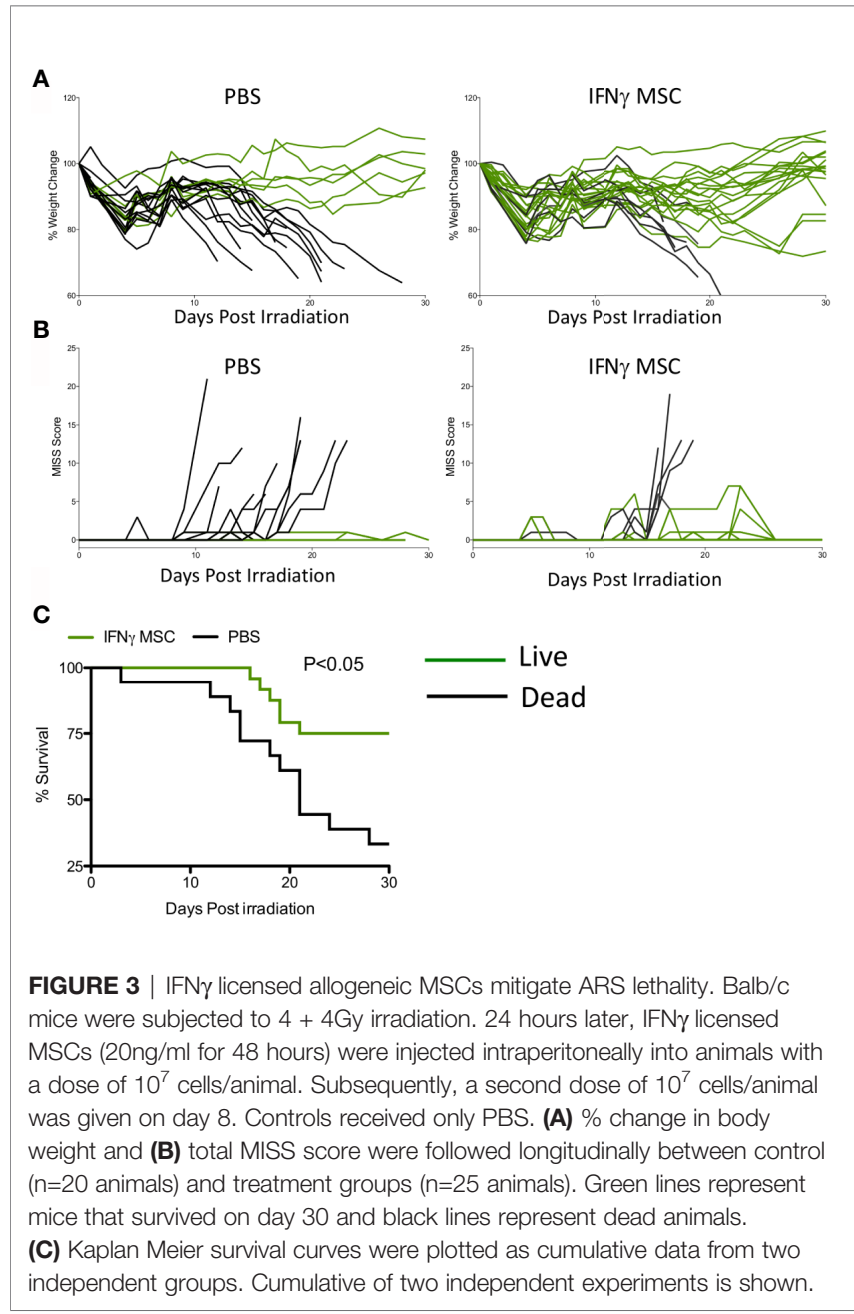

to $1 \mathrm{X}^{6} 0^{6}$ (Figure $4 \mathrm{~B}$ ) and $0.5 \times 10^{6}$ (Figure 4C) splenic T cells per animal to cause less severe GvHD, $10^{7}$ IFN $\gamma$ prelicensed MSCs derived from C57BL/ 6 animals given on days 2, 8 or days 1,3 5 post BMT did not impact GvHD (Figures 4B, C). Altogether, IFN $\gamma$ licensed allogeneic MSCs do not impact GvHD after MHC mismatched BMT.

\section{DISCUSSION}

MSC based animal model studies are complicated for testing of human MSCs since immunocompetent animals may reject human cells and cytokines generated by human MSCs may not cross-react well with murine cytokine receptors. Despite these caveats, in vivo mouse studies have provided evidence of human MSCs mitigating inflammation and injury, but xenogenecity did confound assessment of in vivo MSC potency. In contrast, use of murine MSCs allows for study in immunocompetent murine models but are limited by potential lack of translatability of observations to potency and functionality of human MSCs as their mechanism of immunosuppression is distinct $(16,19)$. Despite these challenges, murine and human MSCs share some 


\section{A}
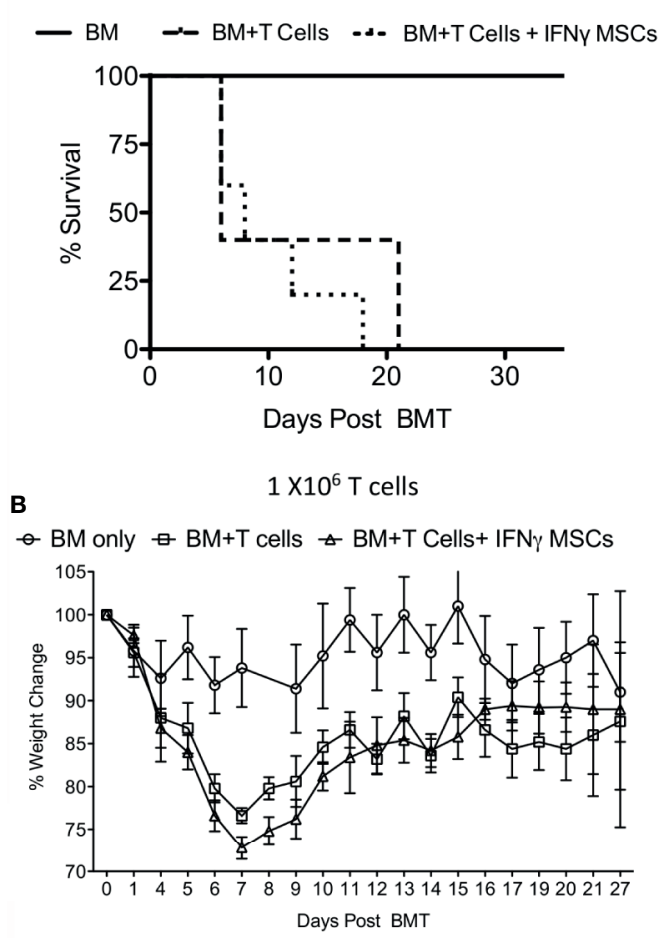

C

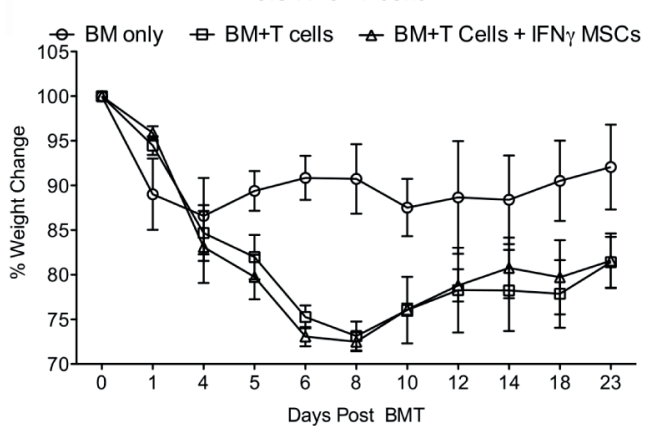

FIGURE 4 | IFN $\gamma$ licensed allogeneic MSCs do not mitigate GvHD from MHC mismatched allogeneic bone marrow transplantation. 4 + 4Gy irradiated Balb/c animals were transplanted with $5 \times 10^{6} \mathrm{~T}$ cell depleted bone marrow and (A) $2 \times 10^{6}$ (B) $1 \times 10^{6}$ and (C) $0.5 \times 10^{6} \mathrm{~T}$ cells from C57BL/6 animals. Bone marrow alone group were transplanted only with $5 \times 10^{6} \mathrm{~T}$ cell depleted bone marrow from C57BL/6 animals without splenic T cells. IFN $\gamma$ licensed C57BL/6 MSCs (20ng/ml for 48 hours) were injected intraperitoneally into the Balb/c animals transplanted with C57BL/6 bone marrow and T cells on day 2 and day 8 post transplantation. For the experiments with $0.5 \times 10^{6} \mathrm{~T}$ cells, IFN $\gamma$ licensed C57BL/6 MSCs were given on days 1, 3, 5 and 8. Body weight and survival was monitored longitudinally. Each of the experiments with 2 $\times 10^{6} 1 \times 10^{6}$ and $0.5 \times 10^{6} \mathrm{~T}$ cell and BM transplantation and MSC infusion were done independently.

common pathways in mediating tissue regeneration and immunomodulation. Thus, utilization of allogeneic murine MSCs can partly inform clinical relevance.
While MSCs have shown promise for a variety of inflammatory disorders, IFN $\gamma$ licensing of MSCs has the potential to substantially augment MSC engraftment, immunomodulatory properties and regenerative properties (20). Considering the significance of allogeneic/random donor MSCs in acute clinical conditions, we have tested the functionality of IFN $\gamma$ prelicensed allogeneic MSCs in 2 acute animal models of lethal ARS and GvHD. In a lethal ARS model, IFN $\gamma$ licensed allogeneic MSCs prolonged animal survival whereas in a lethal GvHD model, IFN $\gamma$ licensed allogeneic MSCs had no impact. Previous studies have revealed the contradictory role of MSCs in mitigating GvHD in animal models (21). Allogeneic, syngeneic and xenogeneic MSCs have been shown to be ineffective in mitigating GvHD in animal models (22-28). In contrast, some studies have shown that MSCs mitigate GvHD (29-32). While variations in the strain combinations used to generate GvHD could explain the discrepancies, it is also entirely possible that MSCs do not traffic to secondary lymphoid organs and/or GvHD target organs to mitigate the associated systemic inflammation. Another explanation is that murine MSCs may not possess higher immunosuppressive properties compared to human MSCs to have a durable effect on murine donor inflammatory $\mathrm{T}$ cells. In addition, recent study indicate that infused MSCs undergo apoptosis and evoke host phagocytosis, which mitigate GvHD (32). Thus, the relative significance of live and apoptotic MSCs in conferring immunosuppression in modulating GvHD is yet to be confirmed in future studies. We still do not know the mechanism of action of human MSCs in mediating clinical benefit in GvHD patients. MSCs are being infused into the patients thawed from cryopreservation. It is entirely possible that thawed MSCs may undergo apoptosis and evoke an antiGvHD response and this phenomenon yet to be proven in the future studies. Murine and human MSCs differ in their mechanism of action in executing immunosuppression (16, 19). This also could explain why human MSCs have shown benefit in clinical studies of steroid refractory GvHD while murine MSCs have no effect. One of the limitations of our study is that we used MHC mismatched BMT to generate severe GvHD while in the clinic MHC-matched, minor histocompatibility antigen mismatched BMT is typically performed. Further studies in minor histocompatibility antigen mismatched BMT may be warranted. Nevertheless, inefficacy of MSCs in the GvHD animal model does not halt the promise of utilizing human MSCs as cell therapeutics in mitigating GvHD in clinic (7, 33-36).

Previous study had shown that proinflammatory cytokine cocktail (IFN $\gamma$, IL-1 $\beta$, TNF $\alpha$ and IFN $\alpha$ ) activated human skinderived precursors displayed lesser efficacy compared to unstimulated counter parts in mitigating graft vs host response in an animal model (37). In contrast, a recent study has demonstrated that cytokine cocktail (IFN $\gamma$, IL-17, IL-1 $\beta$, TNF $\alpha$ ) stimulated human cord blood tissue derived MSCs (CBti MSCs) improved the outcome of xenogeneic mouse model of GvHD (38). Although the effect of resting CBti MSCs in modulating xenogeneic GvHD is unclear, this approach is 
encouraging since cytokine cocktail primed CBti MSCs showed functionality even after cryopreservation and thawing (38). Utilization of cryopreserved MSCs is feasible when performing MSC therapy in multi center studies though cryopreservation and thawing affect the immunobiology of MSCs (39). Our earlier study also demonstrated that IFN $\gamma$ priming of human bone marrow MSCs prior to cryopreservation protect their functionality immediately post thawing (12). In the present study we did not investigate the effect of freeze thawing on MSC's potency. But future studies are warranted to define the effect of optimal cytokine priming technologies that allows the usage of MSCs immediately thawed from cryopreservation.

Radiation exposure is a potential public health threat for both civilians from accidental nuclear disaster and terrorist attacks, and for patients in clinical settings such as undergoing total body irradiation for BMT. The clinically available, licensed medical products for mitigation of ARS are directed toward supportive care which include (i) prophylactic antimicrobials, (ii) transfusion of platelets and erythrocytes, and (iii) G-CSF or GM-CSF. However, efficacy of these mitigators is limited since blood transfusions of platelets and erythrocytes provide only temporary correction of pancytopenia while recombinant cytokines cannot stimulate lymphocyte recovery needed to protect the host from viral infections. An international workshop on ARS at the National Institute of Allergy and Infectious Diseases (NIAID) and the Institut de Radioprotection et de Sûreté Nucléaire encouraged the use of bone marrow MSCs and their cytokine pre-activated derivatives as radiomitigators (40). Of importance, PLX-R18 (Pluristem Therapeutics, Inc), a placenta-derived random donor off-shelf MSC product, is being tested in an early phase clinical trial as a potential radio mitigation countermeasure. PLX-R18 is given intramuscularly to subjects who got exposure or suspected exposure of IR of $\geq 1$ Gy based on Radiation Emergency Medical Management guidelines (NCT03797040). Preclinical studies have shown that xenogeneic, syngeneic or allogeneic MSCs can protect animals from lethal IR injury from ARS by ameliorating damage to the GI tract, CNS, and lungs (41-53). Our results demonstrate that IFN $\gamma$ licensed allogeneic MSCs mitigate dosimetry grade ARS lethality.

Our bioluminescence imaging experiments have demonstrated that IFN $\gamma$ prelicensing transiently enhances allogeneic MSC survival in the animals when given subcutaneously. However, their persistence was lost at later time points in naïve but not in irradiated animals. IFN $\gamma$ induces adhesive molecules on the surface of MSCs, which include ICAM-1 (54). MSCs also express many integrin molecules and thus it is entirely possible that combination of ICAM-1 and other adhesive molecules enhance the binding of MSCs in the subcutaneous tissue (55). The faster clearance of IFN $\gamma$ licensed allogeneic MSCs in naïve animals indicate that recipient immune system may be rejecting infused IFN $\gamma$ licensed allogeneic MSCs. In lethally irradiated animals, this rejection process is milder compared to naïve animals. We injected MSCs 24 hours post IR and imaged after another incubation with 24 hours. IR induced inflammation and gut seepage of endotoxins may induce transient inflammation, which could explain the low-level persistence of IFN $\gamma$ licensed MSCs. Despite this clearance/low persistence, IFN $\gamma$ licensed allogeneic MSCs provide clinical benefit in mitigating ARS lethality, suggesting that MSC's protective effect are mediated by their both low persistence and clearance.

Our bioluminescence imaging was performed with smaller doses $\left(2 \times 10^{6} /\right.$ each flank) of subcutaneous injections while IR protection experiments were done with larger doses $\left(10 \mathrm{X} 10^{6} \%\right.$ animal) of intraperitoneal injections. Subcutaneous injection is limited to $0.1 \mathrm{ml}$ delivery volume. $10 \mathrm{X} 10^{6}$ MSCs are normally reconstituted into $1 \mathrm{ml}$ volume for intraperitoneal injections. Suspension of $10 \times 10^{6}$ MSCs into $0.1 \mathrm{ml}$ volume for subcutaneous injections is not possible. Hence, we used smaller doses of subcutaneous delivery for bioluminescence imaging. In addition, subcutaneous delivery was performed in order to make a precise analysis on the persistence and evanescence of MSCs within the host allogeneic tissue milieu. Secondly, subcutaneous injections are precise to quantify bioluminescence imaging as the bolus is delivered into the cutis tissular microenvironment. This localized delivery has lower cellular diffusion effect in comparison to the intraperitoneal injections. Nevertheless, intraperitoneal infusion of IFN $\gamma$ prelicensed MSCs in the irradiated animals also exhibit short-term persistence in irradiated animals (Figure S2). Altogether these data suggest that IFN $\gamma$ prelicensed allogeneic MSCs mitigate IR induced lethality despite their low persistence.

We have utilized the intraperitoneal injection approach to deliver maximum number of cells $\left(10 \times 10^{6}\right.$ cells/animal $)$ to identify their therapeutical effect. This is only achievable with intraperitoneal but not intravenous infusion approach. Mouse cannot tolerate more than around $1 \times 10^{6}$ MSCs through intravenous injection. Excessive MSCs in the venous system can cause lung embolism, which leads to the sudden death of the animals immediately post intravenous infusions. Thus, it is not possible to test the functionality of large doses of MSCs if they are given intravenously. Since the potency of mouse and human MSCs are not equivalent due to their differences in the mechanism of action, large doses of mouse MSCs are needed to be tested in the preclinical animal models. In clinical trials, MSCs are intravenously delivered up to $10 \mathrm{X} 10^{6}$ cells per kilogram body weight in patients, which is equivalent to an intravenous infusion of 200,000 cells in a 20 -gram mouse. It is unlikely to get a meaningful therapeutical effect with such a low dose of MSCs in the animal models. Despite these technical challenges, concerns have been raised regarding the intravenous administration of MSCs in some clinical situations, which can cause thromboembolism in patients due to the procoagulant tissue factor (56). Alternative routes of MSC deliveries such as intramuscular or intravascular are needed to be further investigated in the future studies. Thus, although intraperitoneal delivery approach has limitations in clinical translation, it provides a reliable mechanistic tool to test larger doses of MSCs in determining efficacy in the animal models.

ARS can cause hematopoietic, gastrointestinal, cardiovascular, or central nervous system defects (57). Similarly, GvHD is a 
multisymptomatic disease involving visceral organ and tissue such as gut, liver and skin. The principal difference between these two clinical indications is the involvement of allogeneic $\mathrm{T}$ cells in mediating inflammation. GvHD is mainly mediated by allogeneic $\mathrm{T}$ cell inflammation, which is absent in ARS. The contradictory clinical benefit of IFN $\gamma$ licensed allogeneic MSCs in these animal models indicate that host environment plays a major role in determining the potency of MSCs. Animal model studies provide some level of insights on the potency and functionality of MSCs and their derivatives in informing human clinical cell therapy. Our results show a contrast in clinical benefit of IFN $\gamma$ licensed allogeneic murine MSCs in mitigating ARS lethality versus no effect in GvHD. Caution must be exercised in translating animal model cell therapy studies into clinic.

\section{DATA AVAILABILITY STATEMENT}

The original contributions presented in the study are included in the article/Supplementary Material. Further inquiries can be directed to the corresponding author.

\section{ETHICS STATEMENT}

The animal study was reviewed and approved by University of Wisconsin-Madison and Mercer University.

\section{AUTHOR CONTRIBUTIONS}

RC conceived and designed the studies, performed experiments, analyzed and interpreted data, and drafted the manuscript. PB and CC helped with allogeneic bone marrow transplantation experiments. $\mathrm{KN}$ and RK helped with radiation experiments. KK and LD helped

\section{REFERENCES}

1. Kabat M, Bobkov I, Kumar S, Grumet M. Trends in Mesenchymal Stem Cell Clinical Trials 2004-2018: Is Efficacy Optimal in a Narrow Dose Range? Stem Cells Transl Med (2020) 9(1):17-27. doi: 10.1002/sctm.19-0202

2. Moll G, Hoogduijn MJ, Ankrum JA. Editorial: Safety, Efficacy and Mechanisms of Action of Mesenchymal Stem Cell Therapies. Front Immunol (2020) 11:243. doi: 10.3389/fimmu.2020.00243

3. Martin I, Galipeau J, Kessler C, Le Blanc K, Dazzi F. Challenges for Mesenchymal Stromal Cell Therapies. Sci Transl Med (2019) 11(480). doi: 10.1126/scitranslmed.aat2189

4. Moll G, Ankrum JA, Kamhieh-Milz J, Bieback K, Ringdén O, Volk HD, et al. Intravascular Mesenchymal Stromal/Stem Cell Therapy Product Diversification: Time for New Clinical Guidelines. Trends Mol Med (2019) 25(2):149-63. doi: 10.1016/j.molmed.2018.12.006

5. Ankrum JA, Ong JF, Karp JM. Mesenchymal Stem Cells: Immune Evasive, Not Immune Privileged. Nat Biotechnol (2014) 32(3):252-60. doi: 10.1038/ nbt.2816

6. Mastrolia I, Foppiani EM, Murgia A, Candini O, Samarelli AV, Grisendi G, et al. Challenges in Clinical Development of Mesenchymal Stromal/Stem Cells: Concise Review. Stem Cells Transl Med (2019) 8(11):1135-48. doi: 10.1002/sctm.19-0044 with dosimetry experiments. JG provided critical advice on the study. RC, CC, and RK edited the manuscript. All authors contributed to the article and approved the submitted version.

\section{FUNDING}

This study was directly supported by the WES Leukemia Research Foundation (RC). This research was also supported by Mercer University School of Medicine's research funds (RC) and generous support from the Landings Women's Golf Association (Savannah, GA). This work was also supported by National Institutes of Health, National Institute of Diabetes and Digestive and Kidney Diseases award R01DK109508 (JG). This study was also supported by a St. Baldrick's-Stand Up To Cancer Pediatric Dream Team Translational Research Grant SU2C-AACR-DT-27-17, NIH/NCATS UL1TR000427 to the UW ICTR and NIH/NCI P30 CA014520 to the UWCCC, and NIH/NCI R01 CA215461 (CC). Stand Up To Cancer is a division of the Entertainment Industry Foundation. Research grants are administered by the American Association for Cancer Research, the scientific partner of SU2C. The contents of this article do not necessarily reflect the views or policies of the Department of Health and Human Services, nor does mention of trade names, commercial products, or organizations imply endorsement by the US Government. None of these funding sources had any input in the study design, analysis, manuscript preparation or decision to submit for publication.

\section{SUPPLEMENTARY MATERIAL}

The Supplementary Material for this article can be found online at: https://www.frontiersin.org/articles/10.3389/fimmu.2021. 708950/full\#supplementary-material

7. Kurtzberg J, Abdel-Azim H, Carpenter P, Chaudhury S, Horn B, Mahadeo K, et al. A Phase 3, Single-Arm, Prospective Study of Remestemcel-L, Ex Vivo Culture-Expanded Adult Human Mesenchymal Stromal Cells for the Treatment of Pediatric Patients Who Failed to Respond to Steroid Treatment for Acute Graft-Versus-Host Disease. Biol Blood Marrow Transplant (2020) 26:845-54. doi: 10.1016/j.bbmt.2020.01.018

8. Hoogduijn MJ, Lombardo E. Mesenchymal Stromal Cells Anno 2019: Dawn of the Therapeutic Era? Concise Review. Stem Cells Transl Med (2019) 8 (11):1126-34. doi: 10.1002/sctm.19-0073

9. Panes J, Garcia-Olmo D, Van Assche G, Colombel JF, Reinisch W, Baumgart DC, et al. Expanded Allogeneic Adipose-Derived Mesenchymal Stem Cells (Cx601) for Complex Perianal Fistulas in Crohn's Disease: A Phase 3 Randomised, Double-Blind Controlled Trial. Lancet (2016) 388 (10051):1281-90. doi: 10.1016/S0140-6736(16)31203-X

10. Chinnadurai R, Forsberg MH, Kink JA, Hematti P, Capitini CM. Use of MSCs and MSC-Educated Macrophages to Mitigate Hematopoietic Acute Radiation Syndrome. Curr Stem Cell Rep (2020) 6(3):77-85. doi: 10.1007/s40778-02000176-0

11. Guess AJ, Daneault B, Wang R, Bradbury H, La Perle KMD, Fitch J, et al. Safety Profile of Good Manufacturing Practice Manufactured Interferon Gamma-Primed Mesenchymal Stem/Stromal Cells for Clinical Trials. Stem Cells Transl Med (2017) 6(10):1868-79. doi: 10.1002/sctm.16-0485 
12. Chinnadurai R, Copland IB, Garcia MA, Petersen CT, Lewis CN, Waller EK, et al. Cryopreserved Mesenchymal Stromal Cells Are Susceptible to T-Cell Mediated Apoptosis Which Is Partly Rescued by IFNgamma Licensing. Stem Cells (2016) 34(9):2429-42. doi: 10.1002/stem.2415

13. Chinnadurai R, Copland IB, Patel SR, Galipeau J. IDO-Independent Suppression of T Cell Effector Function by IFN-Gamma-Licensed Human Mesenchymal Stromal Cells. J Immunol (2014) 192(4):1491-501. doi: 10.4049/jimmunol.1301828

14. Kim DS, Jang IK, Lee MW, Ko YJ, Lee DH, Lee JW, et al. Enhanced Immunosuppressive Properties of Human Mesenchymal Stem Cells Primed by Interferon-Gamma. EBioMedicine (2018) 28:261-73. doi: 10.1016/ j.ebiom.2018.01.002

15. Krampera M, Cosmi L, Angeli R, Pasini A, Liotta F, Andreini A, et al. Role for Interferon-Gamma in the Immunomodulatory Activity of Human Bone Marrow Mesenchymal Stem Cells. Stem Cells (2006) 24(2):386-98. doi: 10.1634/stemcells.2005-0008

16. Chinnadurai R, Sands J, Rajan D, Liu X, Arafat D, Das R, et al. Molecular Genetic and Immune Functional Responses Distinguish Bone Marrow Mesenchymal Stromal Cells From Hepatic Stellate Cells. Stem Cells (2019) 37(8):1075-82. doi: 10.1002/stem.3028

17. Koch A, Gulani J, King G, Hieber K, Chappell M, Ossetrova N. Establishment of Early Endpoints in Mouse Total-Body Irradiation Model. PLoS One (2016) 11(8):e0161079. doi: 10.1371/journal.pone.0161079

18. Pedersen KH, Kunugi KA, Hammer CG, Culberson WS, DeWerd LA. Radiation Biology Irradiator Dose Verification Survey. Radiat Res (2016) 185(2):163-8. doi: 10.1667/RR14155.1

19. Ren G, Su J, Zhang L, Zhao X, Ling W, L'Huillie A, et al. Species Variation in the Mechanisms of Mesenchymal Stem Cell-Mediated Immunosuppression. Stem Cells (2009) 27(8):1954-62. doi: 10.1002/stem.118

20. Burnham AJ, Daley-Bauer LP, Horwitz EM. Mesenchymal Stromal Cells in Hematopoietic Cell Transplantation. Blood Adv (2020) 4(22):5877-87. doi: 10.1182/bloodadvances.2020002646

21. Tolar J, Le Blanc K, Keating A, Blazar BR. Concise Review: Hitting the Right Spot With Mesenchymal Stromal Cells. Stem Cells (2010) 28(8):1446-55. doi: $10.1002 /$ stem.459

22. Gregoire C, Ritacco C, Hannon M, Seidel L, Delens L, Belle L, et al. Comparison of Mesenchymal Stromal Cells From Different Origins for the Treatment of Graft-Vs.-Host-Disease in a Humanized Mouse Model. Front Immunol (2019) 10:619. doi: 10.3389/fimmu.2019.00619

23. Bruck F, Belle L, Lechanteur C, de Leval L, Hannon M, Dubois S, et al. Impact of Bone Marrow-Derived Mesenchymal Stromal Cells on Experimental Xenogeneic Graft-Versus-Host Disease. Cytotherapy (2013) 15(3):267-79. doi: 10.1016/j.jcyt.2012.09.003

24. Prigozhina TB, Khitrin S, Elkin G, Eizik O, Morecki S, Slavin S. Mesenchymal Stromal Cells Lose Their Immunosuppressive Potential After Allotransplantation. Exp Hematol (2008) 36(10):1370-6. doi: 10.1016/ j.exphem.2008.04.022

25. Sudres M, Norol F, Trenado A, Gregoire S, Charlotte F, Levacher B, et al. Bone Marrow Mesenchymal Stem Cells Suppress Lymphocyte Proliferation In Vitro But Fail to Prevent Graft-Versus-Host Disease in Mice. J Immunol (2006) 176 (12):7761-7. doi: 10.4049/jimmunol.176.12.7761

26. Nauta AJ, Westerhuis G, Kruisselbrink AB, Lurvink EG, Willemze R, Fibbe WE. Donor-Derived Mesenchymal Stem Cells are Immunogenic in an Allogeneic Host and Stimulate Donor Graft Rejection in a Nonmyeloablative Setting. Blood (2006) 108(6):2114-20. doi: 10.1182/ blood-2005-11-011650

27. Zangi L, Margalit R, Reich-Zeliger S, Bachar-Lustig E, Beilhack A, Negrin R, et al. Direct Imaging of Immune Rejection and Memory Induction by Allogeneic Mesenchymal Stromal Cells. Stem Cells (2009) 27(11):2865-74. doi: $10.1002 /$ stem.217

28. Highfill SL, Kelly RM, O’Shaughnessy MJ, Zhou Q, Xia L, PanoskaltsisMortari A, et al. Multipotent Adult Progenitor Cells can Suppress GraftVersus-Host Disease via Prostaglandin E2 Synthesis and Only If Localized to Sites of Allopriming. Blood (2009) 114(3):693-701. doi: 10.1182/blood-200903-213850

29. Chung NG, Jeong DC, Park SJ, Choi BO, Cho B, Kim HK, et al. Cotransplantation of Marrow Stromal Cells may Prevent Lethal GraftVersus-Host Disease in Major Histocompatibility Complex Mismatched
Murine Hematopoietic Stem Cell Transplantation. Int J Hematol (2004) 80 (4):370-6. doi: 10.1532/IJH97.A30409

30. Tisato V, Naresh K, Girdlestone J, Navarrete C, Dazzi F. Mesenchymal Stem Cells of Cord Blood Origin are Effective at Preventing But Not Treating Graft-Versus-Host Disease. Leukemia (2007) 21(9):1992-9. doi: 10.1038/sj.leu.2404847

31. Polchert D, Sobinsky J, Douglas G, Kidd M, Moadsiri A, Reina E, et al. IFNGamma Activation of Mesenchymal Stem Cells for Treatment and Prevention of Graft Versus Host Disease. Eur J Immunol (2008) 38(6):1745-55. doi: 10.1002/eji.200738129

32. Galleu A, Riffo-Vasquez Y, Trento C, Lomas C, Dolcetti L, Cheung TS, et al. Apoptosis in Mesenchymal Stromal Cells Induces In Vivo Recipient-Mediated Immunomodulation. Sci Transl Med (2017) 9(416). doi: 10.1126/ scitranslmed.aam7828

33. Le Blanc K, Rasmusson I, Sundberg B, Gotherstrom C, Hassan M, Uzunel M, et al. Treatment of Severe Acute Graft-Versus-Host Disease With Third Party Haploidentical Mesenchymal Stem Cells. Lancet (2004) 363(9419):1439-41. doi: 10.1016/S0140-6736(04)16104-7

34. Godoy JAP, Paiva RMA, Souza AM, Kondo AT, Kutner JM, Okamoto OK. Clinical Translation of Mesenchymal Stromal Cell Therapy for Graft Versus Host Disease. Front Cell Dev Biol (2019) 7:255. doi: 10.3389/fcell.2019.00255

35. Galipeau J. Mesenchymal Stromal Cells for Graft-Versus-Host Disease: A Trilogy. Biol Blood Marrow Transplant (2020) 26(5):e89-91. doi: 10.1016/ j.bbmt.2020.02.023

36. Kebriaei P, Hayes J, Daly A, Uberti J, Marks DI, Soiffer R, et al. A Phase 3 Randomized Study of Remestemcel-L Versus Placebo Added to Second-Line Therapy in Patients With Steroid-Refractory Acute Graft-Versus-Host Disease. Biol Blood Marrow Transplant (2020) 26(5):835-44. doi: 10.1016/ j.bbmt.2019.08.029

37. De Kock J, Rodrigues RM, Branson S, Verhoye L, Colemonts-Vroninks H, Rombaut $M$, et al. Inflammation Alters the Secretome and Immunomodulatory Properties of Human Skin-Derived Precursor Cells. Cells (2020) 9(4). doi: 10.3390/cells9040914

38. Mendt M, Daher M, Basar R, Shanley M, Kumar B, Wei Inng FL, et al. Metabolic Reprogramming of GMP Grade Cord Tissue Derived Mesenchymal Stem Cells Enhances Their Suppressive Potential in GVHD. Front Immunol (2021) 12:631353. doi: 10.3389/fimmu.2021.631353

39. Moll G, Geissler S, Catar R, Ignatowicz L, Hoogduijn MJ, Strunk D, et al. Cryopreserved or Fresh Mesenchymal Stromal Cells: Only a Matter of Taste or Key to Unleash the Full Clinical Potential of MSC Therapy? Adv Exp Med Biol (2016) 951:77-98. doi: 10.1007/978-3-319-45457-3_7

40. DiCarlo AL, Tamarat R, Rios CI, Benderitter M, Czarniecki CW, Allio TC, et al. Cellular Therapies for Treatment of Radiation Injury: Report From a NIH/NIAID and IRSN Workshop. Radiat Res (2017) 188(2):e54-75. doi: $10.1667 / R R 14810.1$

41. Lange C, Brunswig-Spickenheier B, Cappallo-Obermann H, Eggert K, Gehling UM, Rudolph C, et al. Radiation Rescue: Mesenchymal Stromal Cells Protect From Lethal Irradiation. PLoS One (2011) 6(1):e14486. doi: 10.1371/ journal.pone.0014486

42. Bandekar M, Maurya DK, Sharma D, Checker R, Gota V, Mishra N, et al. Xenogeneic Transplantation of Human WJ-MSCs Rescues Mice From Acute Radiation Syndrome via Nrf-2-Dependent Regeneration of Damaged Tissues. Am J Transplant (2020) 20:2044-57. doi: 10.1111/ajt.15819

43. Linard C, Brachet M, L'Homme B, Strup-Perrot C, Busson E, Bonneau M, et al. Long-Term Effectiveness of Local BM-MSCs for Skeletal Muscle Regeneration: A Proof of Concept Obtained on a Pig Model of Severe Radiation Burn. Stem Cell Res Ther (2018) 9(1):299. doi: 10.1186/s13287018-1051-6

44. Kim A, Shim S, Kim MJ, Myung JK, Park S. Mesenchymal Stem Cell-Mediated Notch2 Activation Overcomes Radiation-Induced Injury of the Hematopoietic System. Sci Rep (2018) 8(1):9277. doi: 10.1038/s41598-018-27666-w

45. Perez JR, Lee S, Ybarra N, Maria O, Serban M, Jeyaseelan K, et al. A Comparative Analysis of Longitudinal Computed Tomography and Histopathology for Evaluating the Potential of Mesenchymal Stem Cells in Mitigating Radiation-Induced Pulmonary Fibrosis. Sci Rep (2017) 7(1):9056. doi: 10.1038/s41598-017-09021-7

46. Lee C, Shim S, Jang H, Myung H, Lee J, Bae CH, et al. Human Umbilical Cord Blood-Derived Mesenchymal Stromal Cells and Small Intestinal Submucosa 
Hydrogel Composite Promotes Combined Radiation-Wound Healing of Mice. Cytotherapy (2017) 19(9):1048-59. doi: 10.1016/j.jcyt.2017.06.007

47. Moussa L, Pattappa G, Doix B, Benselama SL, Demarquay C, Benderitter M, et al. A Biomaterial-Assisted Mesenchymal Stromal Cell Therapy Alleviates Colonic Radiation-Induced Damage. Biomaterials (2017) 115:40-52. doi: 10.1016/j.biomaterials.2016.11.017

48. Maria OM, Shalaby M, Syme A, Eliopoulos N, Muanza T. Adipose Mesenchymal Stromal Cells Minimize and Repair Radiation-Induced Oral Mucositis. Cytotherapy (2016) 18(9):1129-45. doi: 10.1016/j.jcyt. 2016.06.008

49. Wang GH, Liu Y, Wu XB, Lu Y, Liu J, Qin YR, et al. Neuroprotective Effects of Human Umbilical Cord-Derived Mesenchymal Stromal Cells Combined With Nimodipine Against Radiation-Induced Brain Injury Through Inhibition of Apoptosis. Cytotherapy (2016) 18(1):53-64. doi: 10.1016/j.jcyt.2015.10.006

50. Ono M, Ohnishi S, Honda M, Ishikawa M, Hosono H, Onishi R, et al. Effects of Human Amnion-Derived Mesenchymal Stromal Cell Transplantation in Rats With Radiation Proctitis. Cytotherapy (2015) 17(11):1545-59. doi: 10.1016/j.jcyt.2015.07.003

51. Jiang X, Jiang X, Qu C, Chang P, Zhang C, Qu Y, et al. Intravenous Delivery of Adipose-Derived Mesenchymal Stromal Cells Attenuates Acute RadiationInduced Lung Injury in Rats. Cytotherapy (2015) 17(5):560-70. doi: 10.1016/ j.jcyt.2015.02.011

52. Francois M, Birman E, Forner KA, Gaboury L, Galipeau J. Adoptive Transfer of Mesenchymal Stromal Cells Accelerates Intestinal Epithelium Recovery of Irradiated Mice in an Interleukin-6-Dependent Manner. Cytotherapy (2012) 14(10):1164-70. doi: 10.3109/14653249.2012.684378

53. Diaz MF, Horton PLD, Dumbali SP, Kumar A, Livingston M, Skibber MA, et al. Bone Marrow Stromal Cell Therapy Improves Survival After Radiation Injury But Does Not Restore Endogenous Hematopoiesis. Sci Rep (2020) 10 (1):22211. doi: 10.1038/s41598-020-79278-y

54. Espagnolle N, Balguerie A, Arnaud E, Sensebe L, Varin A. CD54-Mediated Interaction With Pro-Inflammatory Macrophages Increases the
Immunosuppressive Function of Human Mesenchymal Stromal Cells. Stem Cell Rep (2017) 8(4):961-76. doi: 10.1016/j.stemcr.2017.02.008

55. Chinnadurai R, Garcia MA, Sakurai Y, Lam WA, Kirk AD, Galipeau J, et al. Actin Cytoskeletal Disruption Following Cryopreservation Alters the Biodistribution of Human Mesenchymal Stromal Cells In Vivo. Stem Cell Rep (2014) 3(1):60-72. doi: 10.1016/j.stemcr.2014.05.003

56. Moll G, Drzeniek N, Kamhieh-Milz J, Geissler S, Volk HD, Reinke P. MSC Therapies for COVID-19: Importance of Patient Coagulopathy, Thromboprophylaxis, Cell Product Quality and Mode of Delivery for Treatment Safety and Efficacy. Front Immunol (2020) 11:1091. doi: 10.3389/fimmu.2020.01091

57. Grammaticos P, Giannoula E, Fountos GP. Acute Radiation Syndrome and Chronic Radiation Syndrome. Hell J Nucl Med (2013) 16(1):56-9.

Conflict of Interest: CC receives honorarium from Nektar Therapeutics.

The remaining authors declare that the research was conducted in the absence of any commercial or financial relationships that could be construed as a potential conflict of interest.

Publisher's Note: All claims expressed in this article are solely those of the authors and do not necessarily represent those of their affiliated organizations, or those of the publisher, the editors and the reviewers. Any product that may be evaluated in this article, or claim that may be made by its manufacturer, is not guaranteed or endorsed by the publisher.

Copyright (๑) 2021 Chinnadurai, Bates, Kunugi, Nickel, DeWerd, Capitini, Galipeau and Kimple. This is an open-access article distributed under the terms of the Creative Commons Attribution License (CC BY). The use, distribution or reproduction in other forums is permitted, provided the original author(s) and the copyright owner(s) are credited and that the original publication in this journal is cited, in accordance with accepted academic practice. No use, distribution or reproduction is permitted which does not comply with these terms. 